\title{
A Systematic Review of Futsal Literature
}

\author{
R. Moore*, S. Bullough, S. Goldsmith, L. Edmondson \\ Sport Industry Research Centre, Sheffield Hallam University, Sheffield, South Yorkshire \\ *Corresponding author: r.moore@shu.c.uk
}

Received January 27, 2014; Revised February 13, 2014; Accepted February 28, 2014

\begin{abstract}
This document systematically reviews literature to provide a summary of evidence based research related to the sport of futsal. The review draws on diverse subjects including coaching, physiological, psychological, technical and tactical elements of the sport as well as reviewing subjects relating to the development of futsal. The methodology included a scoping study and review protocol to systematically review 601 documents relating to futsal; 44 of these documents were reviewed in the study. The review aims to provide a resource for fellow researchers, to study the sport and encourage further English language studies in futsal. To that end, gaps in the literature are highlighted by the researchers, and therefore this document acts as a guide for further study.
\end{abstract}

Keywords: development, sports science, participation, tactics, training, psychology, physiology

Cite This Article: R. Moore, S. Bullough, S. Goldsmith, and L. Edmondson, “A Systematic Review of Futsal Literature." American Journal of Sports Science and Medicine, vol. 2, no. 3 (2014): 108-116. doi: 10.12691/ajssm-2-3-8.

\section{Introduction}

Futsal, a variant of football, is a sport played worldwide at amateur, semi-professional and professional level. The sport has a long standing history, dating back to the 1930's in South America, where it was, and still is known as 'futebol de salao' (translated from Portuguese as 'hall football'). FIFA standardised the sport and branded it the official version of '5-a-side' to create a structure to allow futsal to develop worldwide.

It is clear that futsal continues to grow as a sport. This growth has led to an increased demand for futsal related information, to allow people to better understand the sport and its qualities and intricacies. Particularly, there is a desire for coaches, players, sport scientists and administrators to improve their depth of knowledge, to help them contribute to the development of the sport in their respective countries.

From an academic perspective, it is perceived that there is a lack of research relating to futsal in the English language, especially when considering the vast amount of literature available around football; futsal's sister sport. The following systematic review of literature will be the first of its kind in the English language, and will be a source to explore evidence based research related to futsal. The paper also aims to highlight gaps in the literature and to encourage fellow researchers to contribute to the depth of knowledge in the sport.

\subsection{Scoping Study}

An initial scoping study of the literature was conducted to gain a brief overview of the related topics in futsal, including theoretical, practical and methodological history and key discussions relating to futsal.

\subsection{Review Protocol}

A review protocol was set up to define the review to limit individual bias and ensure an efficient process. This enabled a search strategy to be created to establish which literature was to be included or excluded from the review.

The following criterions were identified:

1. Academic relevance (futsal and identified keywords)

2. Only studies produced in the English language

3. The publication date was post 1990 onwards.

4. The publication length was required to be more than 3 pages.

\subsection{Conducting a Review}

When conducting a systematic review, each stage should be recorded and traceable allowing for the study to be replicated. The first step in the review process was to identify electronic databases which would reveal a broad array of literature relating to futsal. The following list of databases were judged as being suitable for the purposes of the study:

1. Sport Discus - a comprehensive database covering sport.

2. Scopus - multidisciplinary database for over 18,000 peer reviewed periodicals covering a broad range of subjects.

3. Web of Science - large index of scientific, technical, social sciences literature.

4. Business Source Premier - database covering subjects such as sport management and finance.

5. PsychINFO - psychological literature including sports related fields.

6. Physical Education Index - coverage includes health, coaching, sport sociology and sport medicine.

7. Sage Journals Online - journal articles in various disciplines. 
The next step in the process, was to identify an appropriate list of search terms, identified from the scoping study. These search terms were then used in search strings, input into the databases, to maximise the opportunity to identify literature linked to futsal. The following search terms were chosen by the review panel:

1. Futsal

2. Sport Science

3. Training

4. Participation

5. Development

6. Education

7. Professional

8. Football

Search strings were then created from these search terms to provide a list of literature relevant to the keywords and linked to futsal. Seven search strings were identified by the review panel:

1. Futsal AND sport science

2. Futsal AND training

3. Futsal AND participation

4. Futsal AND development

5. Futsal AND education

6. Futsal AND professional

7. Futsal AND football

\subsection{Results of Literature Search}

Overall, 836 documents were returned. Of these, 235 were duplicates. 601 documents were reviewed and 44 were referred to in the document.

\section{Review of Literature}

\subsection{Futsal Participation}

To understand the characteristics of futsal, it is essential that its participants, the people who embrace the sport are studied, to determine who participates, where, why and how? FIFA's 'Big Count' [1] study states that 265 million male and females worldwide are registered with their National Governing Body to play football. In terms of futsal participation, the 'Big Count' indicates that in 2006 just over 1 million male and females registered to play futsal. This is likely to be a conservative figure, given the study only includes players registered with their national football governing body, whereas futsal, in some countries, is governed independent of these organisations. Generally, the evidence base for futsal participation is virtually nonexistent. For example, the literature searches for futsal \& participation returned only 30 studies post 1990, many of which mentioned participation, but were not predominantly participation based studies.

A small number of studies focus on migration, considering the experiences of elite Brazilian futsal players who travel from Brazil to Europe to play professional futsal. Dimeo and De Vasconcellos Ribeiro [2] interviewed professional players using questions based upon three key themes: 'adaptation to the new country in social and sporting terms, questions of national identity, and general questions about their attitudes and plans'. The answers provided by these players suggest that migration has broadly turned out to be a positive experience, although the affinity these players have for their home country was alluded to in the study. Altmann and Dos Reis [3] suggested Brazil is perceived as having a well developed structure for the sport of futsal, which poses the question as to why players from Brazil would choose to migrate to Europe to play futsal. Futsal is a global sport and therefore players will migrate, but further research would enable us to understand why this occurs, where players travel to, and what impact this has on participating nations, particularly as economic and lifestyle reasons are often speculated.

From elite to grassroots participation; the challenges impacting on players can vary considerably, particularly those playing at a minority level. Macbeth [4] examined barriers to participation experienced by partially sighted individuals when accessing opportunities at the grassroots level in Britain. The study found that players had to travel long distances to participate, and had poor awareness of opportunities to play, which presented a socially imposed restriction of activity. Furthermore, the change in the format of football in the British Blind Sport Visually Impaired Football League (BBSVIFL) from five-a-side to futsal, raised further concerns. Although a specific example, this study represents the challenges faced by organisations, clubs and participants in participating in a sport which receives little attention and support in some countries. Furthermore, there is a great need for social studies of this kind to provide an insight into the challenges and opportunities arising in the development of the sport. Generally, further research is required to understand participation trends worldwide as a huge disparity exists between countries.

\subsection{Futsal Development}

The development of futsal, although vague in its description, is of significant interest to people, partly because there is a desire to understand how the sport has become established in certain countries, particularly people based in new futsal territories aiming to progress the sport.

Futsal, however, has a relatively limited body of evidence around the development of the sport, although studies do exist in (or about) a number of countries (Australia, China, Cuba, Brazil and Portugal) focussing specifically on this subject. A study in the WalloniaBrussels region in Belgium outlined that, in order to deliver high performance in sport, governing bodies should be 'developing innovative activities for their members', be proactive in providing elite sport services, and either involve paid staff in decision-making processes around these innovative activities; or 'involve committed volunteers in decision-making processes and delegate activities they are not able to deliver themselves' [5]. Futsal was one of the 49 sports under consideration in this study and the associated strength of the governing body in areas such as strategy was deemed to be a key factor for development. This study provides a good basis for countries to plan and set up their approach to futsal development, dependent upon the resources available.

Other studies in futsal development have taken place to determine how competitive advantage can be gained at the elite level. Benton [6] outlines that, in Australia, the national team were able to qualify for the 2012 FIFA Futsal World Cup in Thailand. This qualification was 
achieved despite limited administrative support and on a small budget. Overall, the study demonstrated that futsal is developing in Australia as more associations become involved in the administrative organisation of the game. Furthermore, an Australia Soccer International publication [7] discussed the future of futsal, reporting that there is a National Football Development Plan which aims to improve and sustain 'the education of future football players, coaches and supporting infrastructures', with key considerations around the development of futsal in the future. The plan also aims to investigate 'whether futsal players are born or made' alongside considerations aimed at developing the future of futsal in Australia.

A researcher [8] studied the competitive futsal structure in Brazil with a view to developing the sport in China. The study found that there were positive characteristics in terms of organisation, chain of command, and precise departmental functions, which contributed to the success of Brazilian futsal competitions. The study found features of multi-level work (e.g. competitions) and good convergence across competitions that have stability and continuity, which ensures that futsal is embedded into the countries sporting culture. A follow up study by the same author [9] proposed a strategy with a series of future development requirements for Chinese futsal, including; continuing to work with colleges and universities to develop futsal, strengthen commercial development, arrange more training for coaches and establish multilevel competition systems (as concluded in the review of the Brazilian system in the 2011 study). Evidently, this is a very broad area of study, and therefore research into developmental procedures undertaken in other sports may help guide future research in this area, to create a blueprint to enable countries to plan a sustainable futsal development programme.

\subsubsection{Development of Futsal Coaching}

To provide more opportunities to play and learn the game, it is crucial that the education of coaches is at the forefront of futsal bodies' plans to develop the sport. Again, there is a limited body of evidence in this area, although a couple of studies that exist provide insight into how the expertise level of futsal coaches can have an impact on several aspects of futsal performance, training and the delivery of futsal specific drills. Serrano et al., [10] examined futsal coaches with different coaching education levels, to assess sports performance factors (technical, tactical, physical and psychological) by analysing the training provided during sessions. Three coaching groups were devised (novice, intermediate and elite) depending on the degree of specific education, coaching experience and the level of the teams that the coaches trained. The results showed significant differences between the novice and elite group of coaches in small-sided games, inferiority games, execution timing, and opposition of the training and drill items. The analysis also showed significant differences between the novice and intermediate group in inferiority games drill items.

Another coaching related study by Moreira et al., [11] observed teaching, learning and training processes by coaches in futsal, and how the application of certain methods influenced, 'the acquisition of procedural tactical knowledge'. The study concluded that training methods that are centred on decision making and development of tactical abilities are more likely to promote 'development of players capable of intelligent and creative actions', which is a key requirement particularly for elite futsal players. This demonstrates that playing the sport does not necessarily lead to the development of intelligent and creative actions, unless coaching actions provide the environment for such development to occur.

Gomes et al. [12], conducted research into factors influencing leadership, cohesion and satisfaction in sporting teams - important factors in creating successful players and teams. This study focussed on 200 athletes from both futsal and football (soccer). Coaches were analysed in order to assess their leadership styles, whereas analysis also took place on athletes' levels of cohesion and satisfaction. The results highlighted that men and women had different preferences in terms of coaches' behaviours and leadership approach. In addition, the authors discovered that females assumed higher levels of social cohesion than their male counterparts. Further research in this area could centre on other sports, to see whether research findings could be transferable to futsal in subjects such as coaching communication, approach to create a conducive environment for futsal players to succeed.

\subsection{Physiological Elements of Training and Competition}

Futsal is a very physically intense sport, and consequently evidence from the literature shows that the physical demands of futsal are important considerations for coaches in applying training for competition. Various authors Castagna et al [13]; Baroni and Leal Jr [14]; Álvarez et al [15]; Karahan [16]; refer to the aerobic and anaerobic requirements in futsal; the different physiologies between players at various competitive levels, and how systems can be trained to improve maximal performance.

Alvarez et al. [15], explored the aerobic fitness of futsal players in different competitive levels, to determine whether aerobic fitness in futsal players is a discriminative variable for futsal success. The maximal oxygen uptake (Vo2max), ventilatory threshold (VT), and running economy (RE, Vo2 at $8 \mathrm{~km}-\mathrm{h}-1$ ) were examined for both professional and semi-professional players. The main finding of this research was that aerobic fitness levels were significantly higher in professional, highly trained players than in lower-level, semi-professional players, suggesting that aerobic fitness may be considered a competitive-level dependent physical variable in futsal. These findings are further supported by Castagna et al. [13], who also studied the match demands of professional futsal. The authors examined the physiological responses and activity pattern for futsal simulated game-play in professional players, and found that futsal played at a professional level is a highly demanding physically intense exercise which stretches the aerobic and anaerobic capabilities of players.

Similarly, Baroni \& Leal Jr [14] carried out a study to evaluate the aerobic capacity of male professional futsal players, using both goalkeepers and on-court players to examine maximal oxygen uptake (Vo2max), second ventilatory threshold (VT 2), speed and heart rate (HR). The study found that on-court players displayed higher Vo2max and VT 2 in comparison to goalkeepers, whilst 
being able to reach these levels at higher exercise levels (speed) than goalkeepers.

These studies highlight the importance of both the anaerobic and aerobic systems in futsal and the differences which exist across different competitive levels, but other studies also consider how these systems can be developed through training to potentially improve performance. Research undertaken by Karahan [16] examined the effects of skill-based maximal intensity interval training on aerobic and anaerobic performance variables among female futsal players. The study found that average anaerobic power, fatigue index and Vo2max improved by $10.7 \%, 22.1 \%$ and $9.6 \%$, respectively. These are interesting findings, as they demonstrate significant improvements which may provide evidence that players can improve their competitive level by training these systems.

These physiological characteristics are an important part of the sport, but previous literature also refers to the technical and tactical nature of the sport. The link between the two is explored by Sampaio et al. [17], who studied training effects in Repeated - Sprint Ability (RSA), and physiological and technical effects of duration and variations in the numbers of players in futsal specific drills. The research was then further developed by Duarte et al. [18], measuring the physiological and technical effects of both duration and variations in the numbers of players in futsal specific drills. Heart rates and technical skills of 8 semi-professional futsal players were recorded during four specific drills; half-court games with official rules, played in 4v4 (10 minutes), 3v3 and 2v2 (4 minutes), with a break of 4 minutes between each repetition. The lowest percentage of HRmax was observed in response to the $4 \mathrm{v} 4$ drill, independent of the exercise duration. In players' number variations, significant differences were found in the percentage of time spent between 65-85\% HRmax, in the number of successive contacts with the ball and number of dribbles. In exercise duration, significant differences were found in the percentage of time spent above $85 \%$ HRmax, in the number of successive contacts with the ball, number of dribbles and number of tackles. The decrease in the number of players and exercise duration resulted in intensity increases and more frequent individual tactical play. The research suggests that coaches have the ability to modify drills, both in terms of numbers and durations, in order to set the drill intensity to a specific level to achieve improved performance.

These aformentioned studies support the view of Gheorghe \& Ion [19] who added that; teams with the best physical training can apply more tactics during competitions, whereas those with poor physical training can negatively affect athletes' will, compromising their learning ability and endurance during both practice and competitions, potentially hindering performance. The number of studies in this field ensures that there is a good base of evidence for further research to take place.

\subsection{Psychological Elements of Training and Competition}

The review of literature thus far indicates how the tactical, technical and physiological elements of futsal combine to create an intense, fast paced sport which creates an environment which requires players to think quickly and make the correct judgments. The psychological impact of players, and in particular, the competitive stress and anxiety in the game of futsal, is a topic that has been analysed by both Geisler and Kerr [20] and Mottaghi et al. [21]. In a study by Geisler and Kerr [20] competition stress and emotions were examined for 65 futsal players in Canada and Japan. It was discovered that Japanese players felt more tension stress in connection with losing than Canadian players, while Canadian participants exhibited stronger effort stress before wins. In the examination of emotions, Canadian's experienced more pleasant emotions after wins than after losses, and more unpleasant emotions after losses than after wins. However, Japanese players reported more unpleasant emotions after wins and more pleasant emotions after losses. Geisler and Kerr [20] suggested that it is the differences in cultural attitudes towards individualism and collectivism that caused such results, highlighting that external influences play a major role in competitive stress and anxiety. This is an interesting finding and suggests that the approach futsal psychology should be planned according to the cultural traits in each country.

More recently, Mottaghi et al. [21] studied the relationship between coaches' and athletes' competitive anxiety and their performance using a sample population of 600 individuals from 60 futsal teams. It was discovered that there was a positive significant relationship between the coaches' anxiety level and sport competition anxiety level in the athletes. The authors concluded that coaches and officials should consider sport competition anxiety among athletes before and during competitions, suggesting that formal and planned competitions, training sessions, and preparation practices can be a major factor assisting to decrease athlete's anxiety. Further research, into the psychological stresses imposed on futsal players, and comparisons with other similar sports would help to understand how the intensity of futsal impacts on players, and how competitive advantage can be gained from coaches adopting the right approach.

\subsection{Studies of Futsal Related Injury}

The prevalence of injuries in contact sports is a subject frequently studied by academics and in this respect futsal is no exception. Several authors have discussed the topic of injury prevalence within futsal including Junge and Dvorak [22] who studied player injuries during 3 consecutive World Cups using 'an established injury report system'. Physicians of participating teams reported all injuries after each match on a standardised injury report form - the average response rate was 93\%. A total of 165 injuries were reported from 127 matches, an incidence record rate of 195.6 injuries per 1000 player hours or 130.4 injuries per 1000 matches. Most injuries were caused by contact with another player and involved the lower extremity (70\%), with most frequent diagnosis being contusion of the lower leg (11\%), ankle sprain (10\%) and groin strain (8\%).

Ribeiro \& Costa [23] analysed the incidence, circumstances, and characteristics of injuries recorded during the $15^{\text {th }}$ Brazilian Sub20 Futsal Championship, demonstrating similar results to the previous research. The study found that contact injuries were predominant in 
65.62\% (21 out of 32 injuries) and injury incidence during the $15^{\text {th }}$ Brazilian Sub20 Futsal Championship was higher than those found in outdoor soccer tournaments. However, a study by Broman, Fearn, \& Wittenberg [24] at the European Maccabi Games 2011, found that the majority of injuries sustained at multi-sport tournaments were muscle and tendon injuries, with 52/88 (59\%) of total medical encounters affecting muscles and/or tendons. The study also found that the sport with the highest risk of muscle or tendon injury was football with $45 \%$ of the total injuries compared with $27 \% \quad(14 / 52)$ for futsal, demonstrating, futsal had a moderate risk of injury, of injuries occurring in this sport. This study demonstrates futsal's similarity with football, in terms of the location of injuries, but also the differences, suggesting that futsal provides an environment where injuries are less likely to occur, compared with football.

Bolling, De, \& Reis [25] found similar findings in relation to the type of injures affecting futsal players with the addition that they found a higher level of incidence in adults, suggesting that the older you are, the more chance you have of sustaining an injury. In terms of gender, Gayardo, Matana, \& da Silva [26] studied the prevalence of injuries in female athletes in the Brazilian National league of futsal reported during the 2010 season. Out of 135 athletes, 73 (54.1\%) presented some form of injury, with lower limb injuries accounting for $86.5 \%$ of the total; $28.9 \%$ on the ankle, $24 \%$ on the thigh and $23.1 \%$ on the knee. No significant differences were studied in terms of the type of injuries sustained compared with previous studies of male futsal players.

There is a substantial body of evidence which refers to the nature of injuries caused, but in order to develop training programmes in an attempt to reduce potential injury, a better understanding of how these injuries are caused is required. In relation to this, a study by Serrano et al. [27], studied 411 Portuguese male and female futsal players of diverse competitive levels, to identify potential causes of injuries in futsal. The results found that ankle sprain injuries had the highest incidence (48.8\%) of injury. The study also found no differences by gender or the position of the player (on the pitch) on the frequency of the injuries, the type or region of the injury. However, there was significant differences between training and competition, with higher incidences of sprains and contractures during training and higher incidence of muscle tears and fractures in competition. Moreover, significant differences were found in the mechanism of injury; with the majority of bone or joint injuries, sprains and fractures, unsurprisingly a result of contact with opponents.

In an attempt to further the research in this field, Reis et al., [28], carried out an evaluation of FIFA's "The 11+" injury prevention program in youth futsal players, examining 36 futsal players (18 control group and 18 intervention group), where the intervention group performed "The 11+" twice per week for 12 weeks, using Isokinetic testing to measure. The study found the intervention group increased quadriceps concentric (14.7\%-27.3\%), hamstrings concentric (9.3\%-13.3\%) and eccentric (12.7\%) peak torque. Also, functional Hamstring: Quadricep ratio improved by $1.8 \%$ to $8.5 \%$, whilst performance improvements were also visible in; Squat Jump (13.8\%), Countermovement Jump (9.9\%), 5-m and 30-m sprint (8.9\% and 3.3\% respectively), agility (4.7\%), slalom (4.8\%), and balance also improved decreasing the number of falls by $30 \%$ in the non-dominant limb. It was concluded that "The $11+$ " can be used as an effective conditioning tool for improving physical fitness and technical performance of youth futsal players.

\subsection{Performance and Tactical Analysis of Futsal}

A variety of studies exist, in the tactical application of futsal and methods to both coach and analyse such actions. This is unsurprising considering that the tactical element of futsal is one of the sports endearing qualities and therefore of particular interest to researchers.

In recent years, training and match analysis has played a major role in supporting the development of modern day football, aiding both coaches and players alike. This area of analysis within futsal is also prevalent although to a lesser degree. Leite [29] analysed the offensive actions of the Portuguese futsal team which resulted in finalisation of play with Portugal in an offensive phase. Three games were analysed during the European Futsal Championship in 2010, which saw the Portuguese team carry out a total of 167 finalisations. A total of 95 finalisations (56.89\%) were originated from the organised or tactical game (OG) actions, 29 finalisations (17.36\%) were from counterattack actions (CA) and 43 finalisations (25.75\%) were from stopped ball (SB) actions. The importance of each action is represented by the total number of goals (13); 2 were scored $(15.39 \%)$ in the OG actions, 5 goals $(38.46 \%)$ in CA actions and 6 goals (46.15\%) in SB actions. Portugal finalised their offensive phase mainly in the OG actions (56.89\%) but the teams effectiveness was low, compared to stopped ball actions (SB), where $15 \%$ of goals were scored. This research is of particular interest to coaches and players influencing the debate around the varied tactical approaches to futsal. Further research is necessary to compare these results with other elite national teams, but to also broaden the base of knowledge to compare offensive approaches to support coaches tactical preparation.

Polidoro et al. [30] developed a pilot study for video analysis of futsal training to see whether a sample of participants who regularly watch video recordings of their own games or specific motor performance patterns are better at learning specific techniques, than a control group of participants who did not. Twenty players with the same technical characteristics were asked to practice twice a week for one year, but only 10 players (sample group) viewed training videos before each practice. Each group was tested at the beginning, during and at the end of the study on three techniques from the fundamentals of play; control of the ball (sole of the foot), driving the ball (dribbling with the sole of the foot) and shooting (from the toe or tip). The findings showed that significant improvement in the execution of the techniques were found in the sample group who used video analysis. Recommendations were made to undertake in-depth study with a larger study sample.

Video technology was also used by Travassos et al., [31], to study how interpersonal co-ordination tendencies of players in futsal constrained performance of passing actions. From 24 digitised video film clips of attacking 
phases in competitive futsal, the results found that; performance of passing actions was constrained by a convergence in interpersonal distance values between players. Pass efficacy seemed to be constrained by changes in interpersonal distance values between the ball carrier and the $2^{\text {nd }}$ defender without a correspondent adaptation in ball velocity. In conclusion, findings suggest three training phases for developing passing performance in futsal by manipulating key constraints in the performance environment relative to the interpersonal distance values between players.

The passing action of futsal players was further explored by Travassos et al., [32] who studied the effects of manipulating the number of action possibilities in a futsal passing task, to understand the representativeness of practice tasks designs. Eight male senior futsal players performed a passing task, where uncertainty on passing direction for the player in possession of the ball was increased in four conditions and compared with passing data from a competitive match. The results showed that; significantly high levels of regularity were observed in predetermined passes in comparison with emergent passes (passes with a high number of possibilities for action). Moreover, similar results were found for ball speed regularity observed between practice tasks with a high number of possibilities for action (emergent passes) and competitive performance. Furthermore, similar results were also observed for passing accuracy in practice tasks with a high number of possibilities for action compared to competitive performance. It was concluded that increases in the number of action possibilities during practice improved action fidelity of tasks in relation to competitive performance. Furthermore, Ren [33] analysed passing characteristics in futsal and identified three main conclusions:

'1) The most-frequently adopted ball passing distance is less than 10m. 2) Stop-pass is the most-frequently adopted ball passing combination in organizing attack in fustal game. 3) Cross pass is the most-frequently adopted passing direction in fustal game. 4) The midfield is mostfrequently used area in the field and the main area for organizing attack' [37].

\subsubsection{Dynamics of Futsal Players}

A characteristic which helps to define the sport is speed of movement and creating space, with good spatial awareness a key characteristic of elite futsal players. It is therefore unsurprising that the dynamics of futsal players is of interest to some researchers, who try to understand how these particular attributes define a top player. Correa et al., [34], Fonseca et al., [35 \& 36], and Vilar et al., [37] have all conducted research into the spatial dynamics of team sports. Team sports represent complex systems: players interact continuously during a game, and exhibit intricate patterns of interaction, which can be identified and investigated at both individual and collective levels according to Fonseca et al., [35]. A study of the spatial dynamics of players' behaviour in futsal was conducted by Fonseca et al., [35]. Nineteen 'plays' of a sub-phase of a futsal game were played in a reduced area (20m squared) from which the trajectories of all players were extracted. Results obtained from a comparative analysis of player's dominant region and nearest teammate distance revealed different patterns of interaction between attackers and defenders, both at the level of individual players and teams. Larger dominant regions were associated more with attackers rather than defenders. Furthermore, these regions were more variable in size among players from the same team but, at the player level, the attackers' dominant regions were more regular than those associated with each of the defenders.

Fonseca et al. [36] stated that in team sports, the spatial distribution of players on the field is determined by the interaction behaviour established at both player and team levels. The distribution patterns observed during a game emerge from specific technical and tactical methods adopted by the teams, and from individual, environmental and task constraints that influence players' behaviour. By understanding how specific patterns of spatial interaction are formed, one can characterise the behaviour of the respective teams and players. Fonseca et al., [36] conducted a study that analysed theoretical patterns of spatial distribution using data collected from 19 futsal trials with identical playing settings. The results from this study indicated that it is possible to identify a number of characteristics that can be used to describe players' spatial behaviour at different levels, namely the defensive methods adopted by the players. Furthermore, Correa et al. [34] conducted a study to investigate and describe how the game of futsal could be characterised as a dynamic adaptive process. A futsal game, which included participation by two amateur teams, was analysed by examining players' individual (space occupied, skills with and without ball) and collective actions (attacks and defences). Results revealed four attack patterns for each team, with four defence patterns for one team and seven for the other team. All attack/defence patterns were performed in an unpredictable manner, with no absolute correspondence between attacks and defences. Similarly to Correa et al., [34], Vilar et al., [37] conducted research in an effort to better understand the pattern-forming dynamics that emerge from collective offensive and defensive behaviour in team sports, suggesting that a quantitative research method and analysis is important in analysis as it is increasingly being used in team sports to better understand performance in these stylized, delineated, complex social systems.

\subsection{The Relationship between Football and Futsal}

Futsal is a global sport in its own right and differs to football greatly in terms of the rules of the game and tactical actions. There is however a lack of research which explores any link between them, which is surprising given that futsal is used in some countries as a football development tool, to develop young footballers' technical and tactical behaviours. A number of studies do however examine the relationship between futsal and football players in relation to morphological and situational characteristics and parameters, yet there is a high degree of disparity between studies. Samija et al., [38] conducted research on the differences in morphological characteristics between soccer players and futsal players using a sample of 42 futsal and 40 soccer players aged 19 to 36. Significant differences were found between the measured morphological (mainly physical) characteristics of soccer players and the same characteristics of futsal 
players. The major differences were that of height, mass and arm span. Interestingly, Jovanovic et al., [39] also conducted research using a sample of 82 subjects: 40 male futsal players and 42 male soccer players, however no significant difference was found among futsal and soccer players in the parameters of morphological characteristics, possibly because, "futsal players (taking part in the study) were mainly ex-soccer players" [39].

A number of researchers, do refer to the influence that the small sided environment has on the development of football and futsal players, per se. For example, Costa et al., [40], Almeida, Ferreira, Volossovitch [41], and Frencken et al., [42] have conducted research into the effect of small sized pitches and small sided games on interactive and tactical team behaviour in both futsal and soccer. Frencken et al., [42] conducted a study in order to evaluate the effect of pitch size manipulations on interactive team behaviour in small-sided soccer games. Small-sided games were played on a number of different sized pitches: a reference game $(30 \times 20 \mathrm{~m})$, length manipulation $(24 \times 20 \mathrm{~m})$, width manipulation $(30 \times 16 \mathrm{~m})$, and a combination $(24 \times 16 \mathrm{~m})$. Three measures quantifying the teams' interaction were calculated: longitudinal interteam distance, lateral inter-team distance, and surface area difference. Frencken et al., [42] concluded that teams seem to adapt their interactive behaviour according to pitch size in small-sided games. Conversely, Costa et al., [40] studied the tactical behaviours performed by youth soccer players in small-sided games according to different goalposts of soccer (6m x 2m) and futsal (3m x 2m) [41]. The players performed 146 tactical actions in the field with goalposts of soccer and 536 in the field with goalposts of futsal. The authors found no statistical difference for tactical principles performed by players in the field with futsal goalposts and soccer goalposts. Almeida, Ferreira, Volossovitch [41] presented a study aimed to analyse the interaction and main effects of deliberate practice experience and small-sided game formats on the offensive performance of young soccer players. The researchers found that experienced players produced longer offensive sequences with greater ball circulation between them, whereas non-experienced players performed faster offensive sequences with a predominance of individual actions. Furthermore, significant differences were observed in the development and finalisation of offensive sequences within each group, when comparing small-sided game formats. Evidence supports that small-sided games can serve several purposes as specific means of training; however, the manipulation of game formats should always consider the players' individual constraints.

Another difference between futsal and football is the size and weight of the balls, with futsal being slightly smaller (size 4) and heavier. Heim et al., [43] studied the use of futsal balls in physical education lessons by comparing them with traditional and other felt indoor footballs. A sample of 423 5th grade students, male and female, tested the different ball types against technical game ability and game awareness. The use of futsal balls was associated with improvements in the areas of assessment tested, with ball-control (of a bouncing ball) being significantly faster than leather and felt balls. Furthermore, use of the futsal ball resulted in the number of touches of the ball increasing for each player, alongside improved offensive play. The authors reported that participants appeared to have 'markedly less fear of the futsal ball in comparison with other types of balls', leading to conclusions that there is a strong level of support to make greater use of futsal balls with young people when playing indoor football.

In countries where football is particularly dominant over futsal, it is important that researchers can evidence the difference between the two. This will ensure that people are clear of the distinctions between sports, particularly features such as player dynamics, technical, tactical and physiological elements, but also to determine whether the sports can complement each other, particularly with regards to youth development.

\subsection{Futsal and Education}

There is a lack of literature about the relationship between football and education, even though it is understood that futsal is a popular sport in some countries played at schools and universities and means of social improvement linked to national programmes.

Storchevoy et al., [44] analysed physical education as a part of education and vocational training in higher educational institutions, aimed at obtaining psychophysical readiness for professional work using applied vocational physical training (AVPT). The study looked to determine the role of futsal classes as it was a popular sport among young students. They suggested that 'futsal classes facilitate high efficiency and reliability of central nervous, muscular, thermoregulatory systems, as well as of auditory and visual analysers and such important qualities for potential civil engineers as general endurance, hand dexterity, responsiveness, vestibular tolerance, volume, distribution and switch of attention, emotional stability and initiative'. This is an interesting study as it considers characteristics of a sport which may impact on the educational development of a young person. Further research is required to understand how futsal can be used to help young people physically, socially and educationally as part of an organised programme of activity.

\section{Conclusion}

The review demonstrates that there is a base of knowledge in futsal particularly with regards to the physiological aspects of the sport; the physical and psychological demands on futsal players and research around sports injury, particularly their occurrence in major competition. The tactical nature of futsal is also researched thoroughly, mainly in respect of methodologies utilising video to analyse characteristics and trends of elite teams and players. Consequently, the majority of literature relates to research around performance, predominantly of elite players. Even so, literature on this subject is hardly comprehensive, and because of this, studies are not comparable; methodologies not standardised, and therefore research often lacks critique. Furthermore, there is a lack of research in key areas, particularly regarding player development, participation and governance of the sport.

There is a need for researchers with an interest in the sport to 'fill the knowledge gaps' to provide the 
information needed to help develop the sport. Fortunately, there are many examples in other sports where research, particularly in terms of participation and governance, can be used to support further research into futsal. There is also a significant body of evidence not available in the English language. If these studies were translated, researchers can expect to have their work exposed to a new audience. It is hoped that this study will provide the opportunity to explore and learn from literature that is available in futsal and overall to encourage researchers to study the sport.

\section{References}

[1] FIFA (2007). Big Count 2006: Statistical Summary Report, FIFA Communications Division, 2007. [Online]. Available: http://www.fifa.com/mm/document/fifafacts/bcoffsurv/bigcount.su mmaryreport_7022.pdf. [Last accessed Jan. 27 2014].

[2] DIMEO, P and DE VASCONCELLOS RIBEIRO (2009). "I am not a foreigner anymore': A micro-sociological study of the experiences of Brazilian futsal players in European leagues”. Movimento [Journal], 15 (2), 33-44.

[3] ALTMANN, H. and DOS REIS, H. H. B. (2013). "Futsal women in South America: Coping trajectories and achievements". Movimento [journal], 19(3), 211-232.

[4] MACBETH, J. L. (2009). Restrictions of activity in partially sighted football: Experiences of grassroots players. Leisure Studies, 28(4), 455-467.

[5] RIHOUX, B., ROBINSON, L., and ZINTZ, T (2013), Nonprofit and Voluntary Sector Quarterly; 42, 4: pp. 739-762.

[6] BENTON, N (2012). Futsal Fever, Australasian Leisure Management, Issue 94, p64.

[7] Football Federation Australia (2009). National Football Development Plan. [Online]. Available http://www.klufc.org.au/publications/ffa-national-footballdevelopment-plan. [Last accessed Jan. 25 2014]; Cited by Australia Soccer International, Jul/Aug 2009, 17 Issue 7, p68.

[8] CHEN, Y,-Z (2011). Preliminary study on characteristics of futsal competition regime in Brazil. Journal of Shandong Institute of Physical Medicine and Sports, 27(5), 63-67.

[9] CHEN, Y, Z. (2012) Development Strategies of Futsal League in China Journal of Chengdu Sport University, 37(7), 2012, 60-63.

[10] SERRANO, J., SHAHIDIAN, S., SAMPAIO, J., \& LEITE, N. (2013). The importance of sports performance factors and training contents from the perspective of futsal coaches. Journal of Human Kinetics, 38, 151-160.

[11] MOREIRA, V.J.P., DA SILVA MATIAS, C.J.A., GRECO, P.J. (2013), Motriz. Revista de Educacao Fisica [Journal], 19 (1), pp. 84-98.

[12] GOMES, A. R., PEREIRA, A. P. and PINHEIRO, A. R. (2008). Leadership, cohesion and satisfaction in sporting teams: A study with Portuguese football and futsal athletes. Psicologia: Reflexao e critica, 21 (3), 482-491.

[13] CASTAGNA, C., D’OTTAVIO, S., VERA, J. G., \& ÁlVAREZ, J., CARLOS BARBERO. (2009). Match demands of professional futsal: A case study. Journal of Science \& Medicine in Sport, 12(4), 490-494.

[14] BARONI, B. M., \& LEAL Jr., E. C. P. (2010). Aerobic capacity of male professional futsal players. Journal of Sports Medicine and Physical Fitness, 50(4), 395-399.

[15] ÁlVAREZ, J. C. B., D'OtTAViO, S., VERA, J. G., \& CASTAGNA, C. (2009). Aerobic fitness in futsal players of different competitive level. Journal of Strength and Conditioning Research, 23(7), 2163-2166.

[16] KARAHAN, M. (2012). The effect of skill-based maximal intensity interval training on aerobic and anaerobic performance of female futsal players. Biology of Sport, 29(3), 223-227.

[17] SAMPAIO, J., MACAS, V., ABRANTES, C., \& IBANEZ, S. J. (2007). Season variation in repeated sprint ability of futsal players. Journal of Sports Science \& Medicine, 6.

[18] DUARTE, R., BATALHA, N., FOLGADO, H., \& SAMPAIO, J. (2009). Effects of exercise duration and number of players in heart rate responses and technical skills during futsal small-sided games. Open Sports Sciences Journal, 2, 37-41.
[19] GHEORGHE, C., \& ION, C. (2011). The futsal players' physical training during the special training period. Gymnasium: Journal of Physical Education \& Sports, 12(2), 125-128.

[20] GEISLER, G. and KERR, J. H. (2007). Competition stress and affective experiences of Canadian and Japanese futsal players. International journal of sport psychology, 38 (2), 187-206.

[21] MOTTAGHI, M., ATARODI, A. and ROHANI, Z. (2013). The relationship between coaches' and athletes' competitive anxiety, and their performance. Iranian journal of psychiatry and behavioral sciences, 7 (2), 68-76.

[22] JUNGE, A and DVORAK, J (2010). Injury risk of playing football in Futsal World Cups. British Journal of Sports Medicine, 44.15 : 1089-1092.

[23] RIBEIRO, R. N., \& COSTA, L. O. P. (2006). Epidemiologic analysis of injuries occurred during the 15th/ Brazilian indoor soccer (futsal) Sub20 team selection championship. [Análise epidemiológica de lesões no futebol de salão durante o $X V$ Campeonato Brasileiro de Seleções Sub 20] Revista Brasileira De Medicina do Esporte [Journal], 12(1), 1e-4e.

[24] BROMAN, D., FEARN, R., \& WITTENBERG, M. (2013). Muscle and tendon injuries at an international multi-sport tournament: European maccabi games 2011. British Journal of Sports Medicine, 47(10), 35-36.

[25] BOLLING, C. S., DE, A. G., \& REIS, D. R. (2011). Indoor soccer's injuries profile and the correlation with game volume. British Journal of Sports Medicine, 45(4), 375-375.

[26] GAYARDO, A., MATANA, S. B., \& DA SILVA, M. R. (2012). Prevalence of injuries in female athletes of Brazilian futsal: A retrospective study. Revista Brasileira De Medicina do Esporte, 18(3), 186-189.

[27] SERRANO, J., SHAHIDIAN, S., DA CUNHA VOSER, R., \& LEITE, N. (2013). Incidence and injury risk factors in portuguese futsal players. Revista Brasileira De Medicina do Esporte, 19(2), 123-129.

[28] REIS, I., REBELO, A., KRUSTRUP, P., \& BRITO, J. (2013). Performance enhancement effects of federation internationale de football association's 'the 11+" injury prevention training program in youth futsal players. Clinical Journal of Sport Medicine, 23(4), 318-320.

[29] LEITE, W. S. S. (2012). Analysis of the offensive process of the portuguese futsal team. Pamukkale Journal of Sport Sciences, 3(3), 78-89.

[30] POLIDORO, L., BIANCHI, F., DI TORE, P., ALFREDO, \& RAIOLA, G. (2013). Futsal training by video analysis. Journal of Human Sport \& Exercise, 8(2), S290-S296.

[31] TRAVASSOS, B., ARAÚJO, D., DAVIDS, K., ESTEVES, P. T., \& FERNANDES, O. (2012). Improving passing actions in team sports by developing interpersonal interactions between players. International Journal of Sports Science \& Coaching, 7(4), 677688.

[32] TRAVASSOS, B., DUARTE, R., VILAR, L., DAVIDS, K., \& ARAÚJO, D. (2012). Practice task design in team sports: Representativeness enhanced by increasing opportunities for action. Journal of Sports Sciences, 30(13), 1447-1454.

[33] REN, D, M., (2013). Research on the Passing Characteristics of Futsal Game. Journal of Beijing University of Physical Education, 36(1), 123-126.

[34] CORREA, U. C., et al. (2012). The game of futsal as an adaptive process. Nonlinear dynamics, psychology, and life sciences (journal), 16 (2), 185-204.

[35] FONSECA, S., et al. (2012). Spatial dynamics of team sports exposed by voronoi diagrams. Human movement science, 31 (6), 1652-1659.

[36] FONSECA, S., et al. (2013). Measuring spatial interaction behavior in team sports using superimposed voronoi diagrams. International journal of performance analysis in sport, 13 (1), 179-189.

[37] VILAR, L., et al. (2013). Science of winning soccer: Emergent pattern-forming dynamics in association football. Journal of systems science and complexity, 26 (1), 73-84.

[38] SAMIJA, K., et al. (2010). The differences in morphological characteristics between soccer players and futsal players. Croatian sports medicine journal, 25 (1), 28-34.

[39] JOVANOVIC, M, SPORIS, AND MILANOVIC, (2011). Differences in situational and morphological parameters between male soccer and futsal - A comparative study. International journal of performance analysis in sport, 11 (2), 227-238. 
[40] COSTA, I., et al. (2010). Analysis of tactical behaviours in smallsided soccer games: Comparative study between goalposts of society soccer and futsal. Open sports sciences journal, 3, 10-12.

[41] ALMEIDA, C. H., FERREIRA, A. P. and VOLOSSOVITCH, A. (2013). Offensive sequences in youth soccer: Effects of experience and small-sided games. Journal of human kinetics, 36 (1), 97-106.

[42] FRENCKEN, W., et al. (2013). Size matters: Pitch dimensions constrain interactive team behaviour in soccer. Journal of systems science and complexity, 26 (1), 85-93.
[43] HEIM, C., FRICK, U., PROHL, R. (2013). Akuteffekte des Einsatzes von Futsalbällen beim Fußballspielen im Sportunterricht Sportwissenschaft 43 (1), pp. 47-55.

[44] STORCHEVOY, N.F., BELIKOV, E.M., MAKSIMENKO, A.V., SMEKHUNOV, A.A. (2013). Mini-futbol kak sredstvo professional'no-prikladnoj fiziceskoj podgotovki studentov techniceskich. vuzov. Gefälligkeitsübersetzung: Minifußball als Mittel der beruflich-angewandten körperlichen Vorbereitung der Studenten an technischen Hochschulen Teoriya I Praktika Fizicheskoy Kultury (9), pp. 38-40. 